\title{
Presentación del libro América para todos los americanos. Prácticas interculturales de Silvia Fernández Hernández y John H. Sinnigen
}

América para TODOs los americanos. Prácticas interculturales es en sí mismo una experiencia estética, en el sentido que lo señala Eguiarte en la segunda sección del libro "... (sensible y racional), mediante una apreciación crítica (reflexiva y fundamentada) (...) ofrece la oportunidad de desarrollar un pensamiento divergente que permite superar frustraciones, y ampliar y enriquecer el sentido de vida" (p.236).

El itinerario de la experiencia estética se establece desde el principio, donde se presentan los primeros trazos de percepción del concepto de interculturalidad, a través de las experiencias de conflicto, marcadas por la diferencia, por la jerarquía y por la comparación en tres viajes: la enseñanza intercultural de segundas lenguas culturas, la interculturalidad crítica en la alfabetización y la enseñanza del arte y la región andino amazónica. Juntas desean comunicarnos la transformación de la representación del fenómeno cultural como "diglosia cultural" (Tubino) y como capital cultural (Bordieu, 1997 [2005]) a una propuesta más equilibrada y justa.

Adriana Medina López Portillo y John H. Sinnigen se preguntan en “Las competencias interculturales en Estados Unidos frente a la interculturalidad en América Latina" ¿Cómo modifica la globalización contemporánea el significado de cultura? ¿Se ha extinguido el biculturalismo? ¿La educación intercultural bilingüe ha logrado una relación equitativa y paralela entre dos culturas? Como agentes de la planificación, las comunidades se constituyen como agentes de la planificación y se empoderan para hacer oír sus voces en un discurso más simétrico, de intercambio donde se negocian las diferencias. En este marco se produce una transformación de las percepciones sobre las culturas que trastocan sus identidades, las de los indígenas pero también las de TODOS, en un intento por alejarse del marco individualista e interpersonal predominante en el mundo cultural actual y dirigirse hacia un marco de igualdad.

El primer trazo, ubicado en la PRIMERA SECCIÓN, La enseñanza intercultural de segundas lenguas y culturas en la uNAM y la UMBC, muestra la relación enseñanza intercultural de segundas lenguas en tres contextos educativos distintos 
y los retos que cada uno de ellos implica para los profesores. La primera contribución, "...existe un universo inmenso de oportunidades..." La educación para la interculturalidad en la enseñanza de L2 en la educación superior en México: ¿preparación para un mundo globalizado o un ejemplo de una nueva desigualdad educativa?" a cargo de Pfleger nos pone en la mesa la accesibilidad a ese inmenso mundo de las oportunidades a través del aprendizaje de una lengua y cuestiona ¿De verdad aprender una segunda lengua en la universidad es una ventana a otra cultura? ¿Hasta qué punto esto se logra sólo enseñando la lengua? ¿Qué mecanismos es preciso echar a andar para que esto suceda? Si los sistemas de creencias y valores se aprenden a través de la socialización, en interacción con el otro, es tiempo de proponer una política intercultural de la enseñanza de lenguas pero también una política transversal de desarrollo de procesos interculturales integrada a la formación profesional en general, en este sentido, una educación intercultural.

Cristina Simón nos remite al mundo de la ficción, desde el que es posible imaginar y experimentar el mundo pero también analizarlo para enriquecer el acervo intercultural en la enseñanza de español como lengua segunda o extranjera. "La literatura como vehículo para la reflexión intercultural en el aula de eL2/ELE" muestra cómo a través de la sensibilización cultural es posible desarrollar en los alumnos la capacidad para entenderse mejor a sí mismos y al mundo que los rodea, reflexionar sobre el impacto que otra cultura les genera, desnaturalizar (comparar las semejanzas y las diferencias) sus propias prácticas ante el otro para lograr ser un hablante intercultural. Una transformación tal requiere de una serie de condiciones como el marco psico-social del lector, sus intereses, expectativas y estado de ánimo.

La tercera contribución en manos de Elizabeth Arévalo Guerrero presenta en "La interculturalidad en el aula de español: Desarrollo de la sensibilidad y competencia comunicativa intercultural en la educación superior estadounidense"los resultados de un trabajo de investigación en la que se sirve de las teorías y escalas de medición desarrolladas por Bennett (1998) y Byram (1997) sobre sensibilidad intercultural y competencia comunicativa intercultural y de los estándares nacionales de lenguas extranjeras en los Estados Unidos (1999) para averiguar si los estudiantes del Curso Intercultural de español desarrollan una sensibilidad intercultural y una competencia comunicativa intercultural. La autora concluye que el desarrollo de la conciencia y del entendimiento no se da de manera simultánea al desarrollo de la fluidez lingüística, sino que son procesos más lentos. También hace patente la necesidad de formar profesores en el desarrollo de estos rubros para acompañar al alumno en el proceso reflexivo sobre su y otra/s cultura/s. 
Finalmente, para cerrar esta sección, Medina reporta "Prácticas interculturales en el aula universitaria: Ligando la teoría a la práctica", utilizando las teorías de Allport para la reducción de prejuicios(1979), de Kolb sobre el desarrollo organizacional del aprendizaje experiencial (1984), de Hall sobre el inconsciente cultural (1989) y de las seis etapas en el desarrollo de la experiencia de lo "diferente" de Bennett (1993) conforma un proyecto de un semestre llamado "participante cultural", que los acompañe en el proceso de aprendizaje (sentir, percibir, pensar y hacer) de un curso de español que incluye un componente de comunicación intercultural que se discute en cada sesión. El participante cultural "es una persona desconocida- o casi desconocida- de una cultura diferente de la del estudiante, de quien va a aprender aspectos importantes de su cultura y de la persona misma, y con quien van a compartir aspectos de sí mismos." Se propone una estructura de doce pasos que busca el acercamiento al otro de manera aproximativa. Los resultados reportados son muy positivos y refleja la eficacia de la reflexión sobre los conceptos de estos autores en combinación con el aprendizaje experiencial que da continuidad a las prácticas en el salón de clase y las convierte en prácticas sociales, muy convenientes a la creación de un mundo abierto a la incertidumbre y a la celeridad de cambios y de interactuantes.

El segundo trazo corresponde a la SEGUNDA SECCIÓN, intitulada La interculturalidad crítica en la alfabetización y la enseñanza del arte.

En “La diversidad cultural y la discriminación en México: El caso de los indígenas" “La diversidad cultural y la discriminación en México: El caso de los indígenas" Chavero nos pone al tanto del carácter discriminatorio aprendido e internalizado desde culturas ancestrales, lo cual ha devenido en prácticas discriminatorias inconscientes de las que muy poco nos percatamos y que forman parte del discurso y de nuestras conductas. Hacer visible este rasgo es un deber en la educación formal e informal, pero una vez hecho visible también es imperativo enfocarse en procesos de interacción dirigidos a la negociación de las diferencias más que a la tolerancia del otro. Abatir la indiferencia, la invisibilidad y promover acciones orientadas a observar ciertos principios como el de igualdad-diferencia (unidad en la diversidad), el respeto (reconocimiento, valoración y respeto del otro), la sensibilidad humana (revisión crítica de las actitudes), el espíritu solidario (todos estamos interconectados, reciprocidad), la no discriminación (derecho a la no discriminación), interculturalismo crítico (la interculturalidad para todos). Lo anterior implica una apertura en la construcción de la identidad individual y colectiva. 
La segunda contribución a esta sección, "Autoestima y sentido de pertenencia: la experiencia con el arte en secundarias públicas en Santa Fe, Ciudad de México" de María Estela Eguiarte Sakar nos muestra un ejemplo de aplicación de la propuesta de Chavero, con respecto a la discriminación de clase en la Ciudad de México y los efectos que este tipo de discriminación tienen sobre los jóvenes. En este caso, la autora reporta una práctica de clase de alumnas que se forman como profesionales de la Historia del Arte. Varias generaciones de alumnas de la licenciatura en Historia del Arte de la Universidad Iberoamericana han llevado a cabo prácticas en el primer año de secundaria pública en Santa Fe. En este contexto se ha detectado adolescentes con baja autoestima y se ha trabajado la relación entre las emociones y el arte para ayudar a transformar la idea de que el arte es sólo accesible a los privilegiados o a las élites. Al mismo tiempo, esta práctica ha propiciado la expresión de las emociones de los adolescentes a través de la expresión artística.

Frente al resquebrajamiento de los valores y creencias, los rituales tradicionales se ven trastocados en su esencia y en vías de extinción. En el “Levantamiento o promesa: ritual totonaco de solidaridad familiar en tiempos de globalización" Alba H. González Reyes propone una convivencia complementaria y negociada de la tradición, a través de una política pública que considere el desarrollo humano equitativo para las mujeres, a través de prácticas culturales dentro de los ámbitos de la salud en la región del Centro Norte de Veracruz. Otro ejemplo de desarrollo de políticas públicas para el desarrollo sustentable es "Aportes de una experiencia de educación indígena al diseño de la política de inclusión educativa en una gran ciudad" de Rocío Minerva Casariego Vázquez en el cual se reporta una experiencia exitosa de política pública de inclusión y equidad educativa en el Distrito Federal. La conformación del currículo es justamente un ejemplo de la articulación de las prácticas comunitarias para resolver problemas educativos de las comunidades que no pueden asistir a la educación regular debido a sus situaciones particulares de vida. Dentro de este espacio, los participantes se constituyen como agentes de la planificación mediante la instalación de Centros Comunitarios y Figuras Facilitadoras. La propuesta didáctica comprende cuatro elementos: propuesta didáctica educativa, propuesta de formación de figuras docentes, propuesta de evaluación, acreditación, certificación y revalidación de los aprendizajes y una propuesta de seguimiento a la formación y a la operación. El éxito principal de este proyecto ha sido la vinculación por medio de organizaciones, a través de una negociación realizada en el marco de la normatividad que rige el programa Acciones de Inclusión y Equidad Educativa de la Secretaria de Educación del Distrito Federal. En este sentido, la apertura a la negociación y el establecimiento de la norma- 
tividad sobre la base del respeto del otro ha hecho posible la atención a estos grupos de personas para ofrecerles una educación acorde con sus necesidades, donde alfabetización se resignifica como un proceso dinámico, sustentado en la alteridad, que integra la diversidad y que se sustenta en la solidaridad, que parte de situaciones concretas, que implica corresponsabilidad, que se apoya en la participación social y que promueve la autogestión de las comunidades hacia un desarrollo autónomo.

Silvia Fernández Hernández nos refiere, en “Los hacedores de imágenes. Interculturalidad y equidad en el dibujo infantil indígena" que, a través de una actividad lúdica, centrada en el saber-hacer y en el saber-ser, lo maestros identifican prototipos culturales, sociales e individuales de lo indígena para el diseño de estrategias de aprendizaje encaminadas a expresar el entorno indígena al elaborar el contenido e imágenes para ilustrar una colección de 18 libros de 500 cuentos indígenas de 34 etnias distintas editado por el Consejo Nacional de Fomento Educativo (CONAFE). Lo anterior buscaba atender comunidades de grupos menores a 100 habitantes, mediante el Programa de Atención Educativa a Población Indígena PAEPI. La experiencia refleja una práctica de equidad y de intercambio intercultural entre los actores involucrados en la elaboración de estos libros, otra buena práctica de la política pública.

Finalmente, culminamos a lectura de esta sección a través de la mirada pictórica de las comunidades zapatistas de Cristina Hijar González en el capítulo intitulado “Los murales comunitarios. Dimensión estética del movimiento zapatista" y la idea del sujeto político constituido, a través de su arte en un acto de enunciación que lo empodera y lo hace participante en la denuncia de la desigualdad, la cual adquiere dimensiones territoriales descomunales y que pone en tela de juicio la localidad de las demandas y lo convierte en un demanda global que igual resuena en Chiapas que en Aguascalientes que en todo el mundo. La producción murales comunitarios participativos es una manifestación de creatividad colectiva, donde se incorporan objetos emergentes que conforman una identidad inacabada, siempre en constante movimiento.

La tercera pincelada la constituye una serie de artículos de la región andino amazónica, los cuales dan cuenta de la discusión sobre el concepto de interculturalidad en el contexto sudamericano. Fidel Tubino "Del interculturalismo funcional al interculturalismo crítico" nos plantea un movimiento hacia el intercultualismo crítico, ya que el interculturalismo funcional no considera el estado de pobreza y marginación en la que viven los pueblos latinoamericanos y magnimiza la desigualdad, los etereotipos y la jerarquización de la sociedad 
en una relación diglósica. En contraste, el interculturalismo crítico propone un ejercicio de introspección para repensar las relaciones marcadas por el interculturalismo funcional, ya arraigado en las prácticas sociales de los individuos y ubicar prácticas de negociación de las diferencias en un diálogo simétrico entre culturas; es decir, a través de la construcción de una ciudadanía.

Por su parte, Claudia Peña "Un pueblo inminente. El populismo autonomista en Santa Cruz, Bolivia" nos lleva al campo de la política boliviana en donde por vez primera el fenómeno político, en este caso la movilización cruceña de Santa Cruz, se establece con un rasgo de flexibilidad e incertidumbre y al mismo tiempo una serie de actores y sucesos aparentemente desconectados como la demanda por la autonomía se dan cita en este movimiento. A partir de la perspectiva de Laclau (2005), la autora nos presenta un análisis del concepto de movimiento social y pone de relieve su imposibilidad para aprehender la lucha política en Bolivia en toda su complejidad y dinamismo. En su lugar nos introduce al carácter provisional del populismo como una categoría de análisis en constante tensión entre la equivalencia y la diferencia y nos propone la autonomía como un nodo que amalgama o hegemoniza de manera momentánea la situación política boliviana: la diversidad de necesidades y de intereses provenientes de grupos antagónicos, en una unificación simbólica y que constituye un significante vacío. Las necesidades e intereses no satisfechos confluyen en la figura de Evo Morales. Entender la dinámica de la lógica política actual, en el sentido precario y contingente y flexible de los conceptos es crucial ante la complejidad y la celeridad con la que cambia la constitución momentánea del juego político.

\section{En "Matrices civilizatorias y la interculturalidad en Bolivia" Simón Yam-} para H. nos habla de que la Constitución Política del Estado (CPE) en Bolivia no parece haber transformado la práctica monista en su discurso ni en las prácticas, ya que no observa con detenimiento su propio contexto social, ni cultural; en el cual confluyan la visión occidental y la latinoamericana, en una lectura complementaria de "sistemas de valores intercivilizatorios." (404). En este sentido, la autora propone una nueva lectura de la historia y desde una reemergencia de sistemas de valores en la que se transite de una visión pluri y multicultural a una intercultural, en una relación de complementaridad de la visiones en aras de construir la interculturalidad y no un monismo cultural desarticulado.

Finalmente, en "La construcción de la interculturalidad en el Ecuador: Retos para las humanidades" Jhon Stolle McAllister nos plantea retos para las humanidades a partir de su reflexión sobre la Confederación de Nacionalidades 
del Ecuador (CONAIE), el movimiento indígena más grande en el Ecuador. A pesar de que esta Confederación ha luchado por los derechos de las etnias a las que representa, ésta también ha dejado fuera a otros grupos vulnerables que no pertenecen a estas etnias y que también tienen necesidades similares. El autor propone un ejercicio de aplicación de dos principios: el principio filosófico del buen vivir (sumak kawsay) y la observación del ejercicio propio de hacer investigación (como lo ha propuesto ya el mismo Bordieu, 1997 [2005]). En este sentido, el investigador precisa desarrollar la capacidad de reinventarse a partir del descubrimiento del otro y el diálogo intelectual constructivo, abierto a la legitimización del conocimiento y respeto del otro y en la distribución equitativa de los recursos y del poder, de convivencia simétrica de diversas culturas en un diálogo de intercambio simbólico, de experiencias y de significados. Con respecto a los agentes de la planificación intercultural, esa sensibilidad ayudaría a una toma de decisiones más incluyente, fundamentada en el conocimiento del contexto cultural, social, político, económico y lingüístico.

En conclusión, si en palabras de Eisner la experiencia estética sensibiliza al ser humano en su experiencia con la realidad a través de su capacidad para desarrollar el proceso imaginativo, entonces puedo decir que el proceso de lectura de esta obra es un arte. El viaje por sus páginas ha desatado una serie de reflexiones, emociones, sensaciones y de experiencias que sin duda me hacen percibir el mundo de manera diferente. $Y$ es el roce apenas instantáneo con estas sensaciones que me permite construir mis propios murales, individuales y colectivos. 
BiBLIOGRAFÍA

AlLPORT, G. (1979) The nature of prejudice (25th anniversary edition). Massachussetts: Addison_Wesley Publishing Company.

BENNETT, M. (1993)"Towards ethnorelativism: A developmental model of intercultual sensitivity." En Education for the intercultural experience. (ed. Michael Paige). Yarmouth, ME: Intercultural Press, pp. 21-71.

(ed.) (1998) Basic concepts of intercultural communications: Selected readings. Yarmouth, ME: Intercultural Press.

BYRAM, M. (1997) Teaching and assessing intercultural communicative competence. Clevedon, England: Multilingual Matters.

Bordieu, (1997) [2005] Capital cultural, escuela y espacio social. México: Siglo XXI. Estándares nacionales de lenguas extranjeras en los Estados Unidos (1999) HALL, E. (1989) Beyond Culture. New York: Anchor Books.

KoLB, D. (1984) Experiential learning: Experience as a Source of Learning and Development. New Jersey: Prentice Hall.

LaClaU, E. (2005) On Populist Reason. London and New York: Verso. 